\title{
AVALIAÇÃO DE PROGÊNIES DE MEIOS-IRMÃOS DA POPULAÇÃO DE MILHO CMS-453 NO NORDESTE BRASILEIRO'
}

\author{
HÉLIO WILSON LEMOS DE CARVALHO², PAULO EVARISTO DE OLIVEIRA GUIMARÃES ${ }^{3}$, \\ MARIA DE LOURDES DA SILVA LEAL ${ }^{2}$, PAULO CÉSAR LEMOS DE CARVALHO ${ }^{4}$ e MANOEL XAVIER DOS SANTOS ${ }^{3}$
}

\begin{abstract}
RESUMO - Três ciclos de seleção entre e dentro de progênies de meios-irmãos foram realizados na população de milho Zea mays L. CMS-453, de alta qualidade protéica, no período de 1995 a 1997, no Nordeste brasileiro, visando à obtenção de um material mais produtivo, melhor adaptado, portador de caracteres agronômicos desejáveis, com altos teores de triptofano e lisina na proteína, para divulgação na região. As 196 progênies de cada ciclo foram avaliadas em látice 14 x 14, com duas repetições, e realizaram-se as recombinações das progênies selecionadas, dentro do mesmo ano agrícola, de modo a se obter um ciclo/ano. As magnitudes das estimativas dos parâmetros genéticos decresceram do ciclo original para o ciclo I de seleção, registrando-se um acréscimo do ciclo I para o ciclo II. Os altos valores dessas magnitudes, associados às altas médias de produtividade das progênies e aos ganhos médio esperado e obtido com a seleção entre e dentro de progênies, por ciclo de seleção de $11,62 \%$ e 3,0\% respectivamente, evidenciam o grande potencial da população em responder à seleção, o que permitirá a obtenção de um material mais produtivo e melhor adaptado às condições edafoclimáticas da região. Os teores de triptofano e lisina na proteína, na média dos três ciclos de seleção foram de $0,88 \%$ e 3,91\%, respectivamente, o que confere alta qualidade protéica à população CMS-453.
\end{abstract}

Termos para indexação: Zea mays, seleção, métodos de melhoramento, ganho genético.

\section{EVALUATION OF PROGENIES OF HALF-SIBS OF THE CORN POPULATION CMS-453}

\begin{abstract}
Three cycles of selection among and within the progenies of half-sibs were realized in the corn population CMS-453, for high protein quality, in the period of 1995 to 1997, in the Northeastern Brazil, with the objective of obtaining more productive germplasm, well adapted, with good agronomic characters, high percentage of tryptophan and lysine the protein to be utilized in the region. The 196 progenies, in each cycle, were evaluated in a 14 x 14 lattice, with two repetitions, doing the combination of the selected progenies in the same agricultural year, in the way of obtaining a cycle each year. The magnitude of the estimated genetic parameters decreased from the original cycle to the selection cycle I, increasing from cycle I to cycle II. The high values of these magnitudes associated with the high productivity means of the progenies and with the expected and obtained averaged gain from the selection among and within progenies per selection cycle of $11.62 \%$ and $3.0 \%$, respectively, show the high potential of the population to respond to selection which will permit to attain a higher production and a material better adapted to the regional environment. The percentages of tryptophan and lysine in the protein, in average of the three cycles of selection were $0.88 \%$ and $3.91 \%$ giving a high genetic quality for the CMS-453 population.
\end{abstract}

Index terms: Zea mays, selection, breeding methods, genetic gain.

\footnotetext{
${ }^{1}$ Aceito para publicação em 24 de março de 2000.

${ }^{2}$ Eng. Agrôn., M.Sc., Embrapa-Centro de Pesquisa Agropecuária dos Tabuleiros Costeiros (CPATC), Caixa Postal 44, CEP 49001-970 Aracaju, SE. E-mail: helio@ cpatc.embrapa.br

${ }^{3}$ Eng. Agrôn., M.Sc., Embrapa-Centro Nacional de Pesquisa de Milho e Sorgo (CNPMS), Caixa Postal 151 CEP 35701-970 Sete Lagoas, MG. E-mail: xavier@cnpms.embrpa.br

${ }^{4}$ Eng. Agrôn., M.Sc., Escola de Agronomia, Universidade Federal da Bahia (UFBA), Caixa Postal 82, CEP 44380-000 Cruz das Almas, BA.
}

\section{INTRODUÇÃO}

Apesar do maior teor dos aminoácidos essenciais triptofano e lisina em genótipos de milho opaco-2, os materiais contendo o referido gene não foram bem aceitos pelos agricultores, em face de sua aparência opaca e textura farinácea, o que resulta em menor densidade dos grãos, menor produtividade e maior susceptibilidade a pragas, doenças e danos mecâni- 
cos. Segundo Vasal et al. (1980), citados por Magnavaca et al. (1988), as desvantagens do milho opaco-2 foram superadas pela seleção de variedades estáveis, portadoras de endosperma vítreo após 6 a 7 ciclos de seleção. Tais variedades foram obtidas a partir de compostos de base genética ampla e seleção recorrente para produção, endosperma vítreo e altos teores de lisina e triptofano na proteína do endosperma, no Centro Internacional de Mejoramiento de Maiz y Trigo (CIMMYT).

Essas novas populações de milho despertaram novamente o interesse dos melhoristas, por serem tão produtivas quanto as do milho comum, apresentando grãos de alto valor energético e com proteína de maior valor biológico. A utilização desses materiais em regiões onde a população de baixa renda apresenta graves problemas de desnutrição provocada, basicamente, por um déficit protéico, é de fundamental importância, pela sua utilização na suplementação da dieta alimentar e, na formulação de rações mais baratas para animais monogástricos. Considerando que o milho é largamente cultivado e consumido no Nordeste brasileiro, nas suas mais diversas formas, a utilização de variedades de alta qualidade protéica implica maior fornecimento de proteínas de alto valor biológico, a baixo custo de produção, o que, certamente trará benefícios para a população carente de proteínas.

Magnavaca et al. (1988), interessados em verificar o comportamento dos novos materiais contendo o gene opaco-2, em diferentes regiões produtoras de milho no Brasil, introduziam 23 populações do Centro Internacional de Mejoramiento de Maiz y Trigo (CIMMYT). Após avaliações em seis locais, no ano agrícola de 1984, concluíram que essas populações mostraram alta produtividade média de espigas, com possibilidade de serem utilizadas como materiais básicos na obtenção de variedades de alta qualidade protéica, aceitas pelos agricultores.

A eficiência do método de seleção entre e dentro de progênies de meios-irmãos tem sido comprovada por diversos autores quanto às magnitudes dos parâmetros genéticos, especialmente, a variância genética aditiva e os ganhos esperados por seleção para a produtividade de grãos. Assim, ganhos de 13,6\% e 9,4\% por ciclo de seleção foram obtidos por Paterniani (1967) com a população de Dente Paulista, e por Webel \& Lonquist (1967), citados por Paterniani (1968), respectivamente. Os referidos autores consideraram satisfatórios os resultados encontrados. Resultados relevantes foram também obtidos no Nordeste brasileiro com vistas à produtividade em milho, conforme relataram Carvalho et al. (1994, 1995, 1998a) com as variedades BR 5028, BR 5033 e BR 5028. Ganhos menos expressivos foram obtidos por Segovia (1976) e Sawazaki (1979), com as variedades Centralmex e IAC Maia, respectivamente.

As magnitudes da variância genética aditiva têm mostrado grande oscilação em diversos trabalhos envolvendo progênies de meios-irmãos, conforme cita Ramalho (1977), em um levantamento realizado no Brasil até 1976. Essa oscilação foi de 42,0 a 758,0 (g/planta) ${ }^{2}$, com média de 320,0 (g/planta) ${ }^{2}$. Hallauer \& Miranda Filho (1988) também realizaram um levantamento envolvendo 99 ensaios e comprovaram a eficiência desse método de seleção, ressaltando que, além de sua praticidade, ele é capaz de manter suficiente variabilidade genética para propiciar progresso no decorrer dos ciclos de seleção. Valores muito altos da variância genética aditiva foram obtidos por Lordello (1982) com as populações Piranão VD-2 e Piranão VF-1, sendo de $1.995,0(\mathrm{~g} / \text { planta })^{2}$ e $1.725,8(\mathrm{~g} / \text { planta })^{2}$, respectivamente.

Este trabalho teve como objetivo a obtenção de variedade de milho produtiva e adaptada às condições edafoclimáticas do Nordeste brasileiro.

\section{MATERIAL E MÉTODOS}

Uma amostra representativa da população de milho CMS-453 da Embrapa-Centro Nacional de Pesquisa de Milho e Sorgo (CNPMS), em Sete Lagoas, MG, foi plantada no município de Aracaju, SE, pela Embrapa-Centro de Pesquisa Agropecuária dos Tabuleiros Costeiros (CPATC). Na colheita, foram selecionadas 196 progênies de meios-irmãos, seguindo os critérios de competitividade, prolificidade, empalhamento, altura da planta e da espiga, grãos duros, vítreos, de coloração amarela. Foram realizados três ciclos de seleção entre e dentro de progênies de meios-irmãos. O ciclo original foi realizado em 1995, nos municípios de Neópolis e Lagarto (SE) e Cruz das Almas (BA); o ciclo I, no ano de 1996, em Neópolis, Nossa Senhora das Dores (SE) e Cruz das Almas; e o ciclo II, 1997, em Umbaúba (SE) e Nossa Senhora das Dores. 
As avaliações das progênies foram em látice simples 14 x 14, com duas repetições. As parcelas foram formadas por uma fileira de $5 \mathrm{~m}$ de comprimento, com espaçamento de $0,90 \mathrm{~m} \mathrm{e}, 0,20 \mathrm{~m}$ entre covas dentro das fileiras, correspondendo a uma população de 55.555 plantas/ha. A testemunha intercalada, representada pela variedade BR 106, foi colocada sistematicamente dentro de cada subbloco, totalizando 14 parcelas por repetição. Após a realização dos ensaios, retiraram-se as 40 progênies de melhores rendimentos, nas médias dos dois locais e dentro de cada ciclo de seleção. Nessas progênies foram determinados os teores de proteína bruta e dos aminoácidos triptofano e lisina. As determinações químicas nos grãos foram realizadas nos laboratórios da Embrapa-CNPMS. Os teores de proteína bruta foram determinados pelo método de Kjeldahl. As determinações de triptofano e lisina foram feitas conforme método apresentado por Villegas et al. (1984) e Hernandez \& Bates (1969), respectivamente citados por Pacheco et al. (1999). Os valores dessas determinações mostraram que 16 progênies associaram maiores teores de proteína bruta, triptofano e lisina a bons rendimentos de espigas, correspondendo a uma intensidade de seleção de $8 \%$ entre as progênies. Cada ciclo foi completado, então, pela seleção das 16 progênies superiores, as quais foram recombinadas em lote isolado por despendoamento, sendo as fileiras femininas (despendoadas), representadas pelas progênies selecionadas, e as masculinas, representadas pela mistura das duas. Foram selecionadas 200 novas progênies, correspondendo a uma intensidade de seleção de $13 \%$, dentro de progênies. Ressalta-se que as recombinações foram realizadas dentro do mesmo ano agrícola, na época do período seco (novembro, dezembro, janeiro), com irrigação, o que facilitou a obtenção de um ciclo/ano. No campo de recombinação, as fileiras femininas tiveram $25 \mathrm{~m}$ de comprimento. Dentro delas utilizou-se a densidade $0,5 \mathrm{~m}$ entre covas e foram colocadas duas sementes/cova, totalizando 100 plantas/fileira. Após a realização dos ensaios, todos os ensaios e campos de recombinação receberam a adubação de $80 \mathrm{~kg} / \mathrm{ha}$ de $\mathrm{Ne}$ $80 \mathrm{~kg} / \mathrm{ha}$ de $\mathrm{P}_{2} \mathrm{O}_{5}$, nas formas de uréia e superfosfato simples. Todo o $\mathrm{P}$ foi aplicado na semeadura, e o N, em cobertura, na terceira e quinta semana, após o plantio.

Nos ensaios foram avaliados os pesos das espigas, os quais foram ajustados para o nível de $15 \%$ de umidade. Não foi efetuada a correção de estande, em razão de as parcelas mostrarem número final de plantas bem próximo do ideal. Realizou-se, inicialmente, a análise de variância por local, obedecendo-se ao esquema em látice. Após a análise de variância de cada experimento, procedeu-se a análise de variância conjunta, a partir das médias ajustadas de tratamentos, obedecendo ao critério de homogeneidade dos quadrados médios residuais. Os quadrados médios das análises de variância conjunta foram ajustadas para o nível de indivíduos, obtendo-se, assim, todas as variâncias nesse nível e expressas em (g/planta) ${ }^{2}$, conforme Vencovsky (1978) (Tabela 1).

Embora as análises tenham sido feitas em látices, as estimativas dos componentes da variância foram baseadas nas esperanças dos quadrados médios para blocos casualizados, usando os quadrados de tratamentos ajustados e do erro efetivo do látice, conforme método descrito por Vianna \& Silva (1978). Estimou-se o coeficiente de herdabilidade no sentido restrito de médias de progênies $\left(h^{2} \mathrm{~m}\right)$ e de plantas $\left(\mathrm{h}^{2}\right)$, pelas expressões $\sigma_{\mathrm{p}}^{2} / \sigma^{2} \overline{\mathrm{F}}$ e $\sigma^{2}{ }_{\mathrm{A}} / \sigma_{\mathrm{F}}^{2}$, respectivamente. $\mathrm{O}$ índice $\mathrm{b}$ foi determinado pelo quociente $\mathrm{C} . \mathrm{Vg} / \mathrm{C}$.Ve. A estimativa do progresso genético esperado em cada ciclo de seleção foi feita pela fórmula:

$$
\Delta_{\mathrm{g}}=\frac{(1 / 4) \sigma_{\mathrm{A}}^{2}}{\sigma_{\dddot{\mathrm{F}}}}+\text { i.p. } \frac{(3 / 4) \sigma_{\mathrm{A}}^{2}}{\sigma_{\mathrm{d}}}
$$

sendo $\mathrm{i}=1,85$ na primeira relação, e $\mathrm{i}=1,63$, na segunda relação, e $p=1 / 2$. Considerou-se também a relação $\sigma_{\mathrm{d}}^{2}=10 \sigma_{\mathrm{e}}^{2}$, conforme Gardner (1961).

\section{RESULTADOS E DISCUSSÃO}

Nos três ciclos de seleção foram detectadas diferenças significativas $(\mathrm{P}<0,01)$ entre as médias de progênies, indicando a presença de variabilidade genética entre elas. Em todos os ciclos também foi significativa $(\mathrm{P}<0,01)$ a interação progênies $\mathrm{x}$ ambientes, mostrando, assim, os comportamentos diferenciados das progênies nos ambientes. Resultados semelhantes ocorreram em trabalhos similares de melhoramento (Pacheco, 1987; Carvalho et al., 1994, 1995, 1998a). Os valores dos coeficientes de variação ambientais variaram de $9,5 \%$ a $11,7 \%$, conferindo boa precisão aos ensaios (Scapim et al., 1995). Uma maior precisão nos experimentos de avaliação de progênies é bastante desejável, uma vez que, à medida que ela aumenta, melhor será a resposta e o progresso obtido por seleção.

As produtividades médias de espigas obtidas nas progênies avaliadas foram de $5.228 \mathrm{~kg} / \mathrm{ha}$ (ciclo original), $7.213 \mathrm{~kg} / \mathrm{ha}$ (ciclo I) e $4.902 \mathrm{~kg} / \mathrm{ha}$ (ciclo II), o que evidencia alto potencial produtivo da população CMS-453 (Tabela 2). Essas médias corresponderam a $+0,6 \%,-1,6 \%$ e $+8,4 \%$ em relação às produtividades obtidas com a variedade testemunha BR 106, 
nos ciclos original, I e II, respectivamente. As progênies selecionadas superaram a referida testemunha em $14 \%, 11,6 \%$ e $34,8 \%$, nos ciclos original, I II, respectivamente, evidenciando, assim, que progênies cada vez mais produtivas foram sendo obtidas nos ciclos subseqüentes. Especialmente no ciclo II houve acréscimo significativo de produtividade em relação à variedade testemunha BR 106, a qual tem-se destacado em diversos trabalhos no Nordeste brasileiro (Carvalho et al., 1992; Cardoso et al., 1997). Vale ressaltar que os estandes médios observados foram de 22,98 plantas/parcela (ciclo original), 23,53 plantas/parcela (ciclo I) e 23,38 plantas/parcela (ciclo II), correspondendo a 52.827 plantas/ha, 54.092 plantas/ha e 53.747 plantas/ha, respectivamente, estando próximo do estande ideal

TABELA 1. Quadrado médio das análises de variância conjuntas das médias de produção de espigas da população de milho CMS-453 e coeficientes de variação, em três ciclos de seleção1.

\begin{tabular}{lcccc}
\hline Fontes de variação & \multirow{2}{*}{ G.L. } & & Quadrado médio & \\
\cline { 3 - 5 } & & Ciclo original & Ciclo I & Ciclo II \\
\hline Progênies & 195 & $1.144,84^{* *}$ & $408,05^{* *}$ & $304,18^{* *}$ \\
Progênies x locais & $390(195)^{2}$ & $547,60^{* *}$ & $252,98^{* *}$ & $154,97 * *$ \\
Erro efetivo médio & $585(390)$ & 143,30 & 160,27 & 112,62 \\
\hline Média (g/planta) & 102,4 & 133,6 & 11,1 \\
C.V. (\%) & 11,7 & 9,5 & 1,2 \\
\hline 1 Ciclo original: Neópolis, Lagarto e Cruz das Almas, 1995; ciclo I: Neópolis, Cruz das Almas e Nossa Senhora das Dores, 1996; ciclo II: Umbaúba \\
e Nossa Senhora das Dores, 1997. \\
2 Refere-se aos ensaios realizados em dois locais. \\
** Significativo a 1\% de probabilidade, pelo teste F.
\end{tabular}

TABELA 2. Produtividade média da testemunha BR 106 e das progênies avaliadas e selecionadas de milho nos ciclos de seleção original, I e II e médias ajustadas das progênies avaliadas em relação à testemunha. Região Nordeste do Brasil, 1995 a 1997.

\begin{tabular}{|c|c|c|c|c|}
\hline Ciclo $^{1}$ & Material $^{2}$ & $\begin{array}{c}\text { Produtividade média } \\
(\mathrm{kg} / \mathrm{ha})\end{array}$ & $\begin{array}{c}\text { Média ajustada } \\
(\mathrm{kg} / \mathrm{ha})\end{array}$ & $\begin{array}{c}\text { Porcentagem em relação } \\
\text { à testemunha }\end{array}$ \\
\hline \multirow[t]{3}{*}{ Original } & BR 106 & 5.196 & & 100,0 \\
\hline & Progênies avaliadas & 5.228 & 5.713 & 100,6 \\
\hline & Progênies selecionadas & 5.929 & & 114,0 \\
\hline \multirow[t]{3}{*}{ I } & BR 106 & 7.327 & & 100,0 \\
\hline & Progênies avaliadas & 7.213 & 5.567 & 98,4 \\
\hline & Progênies selecionadas & 8.176 & & 111,6 \\
\hline \multirow[t]{3}{*}{ II } & BR 106 & 4.520 & & 100,0 \\
\hline & Progênies avaliadas & 4.902 & 6.063 & 108,4 \\
\hline & Progênies selecionadas & 6.096 & & 134,8 \\
\hline
\end{tabular}

${ }^{1}$ Ciclo original: Neópolis, Lagarto e Cruz das Almas, 1995; ciclo I: Neópolis, Cruz das Almas e Nossa Senhora das Dores, 1996; ciclo II: Umbaúba e Nossa Senhora das Dores, 1997.

2196 progênies avaliadas; 10 progênies selecionadas no ciclo original e 15 progênies selecionadas nos ciclos I e II. 
proposto (55.555 plantas/ha). Não foi feita a correção de estande, apesar de Vencovsky \& Barriga (1992) recomendarem tal procedimento quando não for acusada significância do valor F para o estande de colheita.

As estimativas dos parâmetros genéticos, em todos os ciclos de seleção, constam na Tabela 3, na qual detecta-se uma queda da variabilidade do ciclo original para o ciclo I. A mesma tendência tem sido encontrada em trabalhos similares de melhoramento, utilizando esse tipo de progênie (Webel \& Lonquist, 1967; Paterniani, 1968; Santos \& Naspolini Filho, 1986; Carvalho et al., 1994, 1995, 1998a, 1998b), e ressaltada por Ramalho (1977) como sendo resultante da utilização máxima da variabilidade livre no ciclo original e que corresponde à segregação entre blocos poligênicos. Do ciclo I para o ciclo II foi observado um acréscimo da variabilidade. Incrementos na variabilidade genética no decorrer de ciclos de seleção têm sido relatados por Segovia (1976) e Sawazaki (1979). Para o primeiro autor, o aumento da variabilidade observado a partir do ciclo IV com a variabilidade Centralmex pode ter ocorrido em razão, principalmente, do maior número de progênies selecionadas e recombinadas em cada ciclo, e à modalidade da seleção entre e dentro de progênies de meiosirmãos, um ciclo a cada dois anos. Para Sawazaki (1979), os aumentos ocorridos nos ciclos XI, XII e
XIII, com progênies da variedade IAC-Maya, deveuse à introgressão de algumas linhagens. No entanto, o acréscimo verificado no ciclo VII, com a variedade IAC-Maya, supõe-se, segundo o autor, que foi causado pela liberação de razoável quantidade de variabilidade potencial. Para Mather (1943), citado por Sawazaki (1979), a variabilidade potencial se encontra oculta e se liberta parcialmente no decorrer das gerações. No tocante ao aumento ocorrido do ciclo I para o ciclo II, no presente trabalho, com a população CMS-453, supõe-se que o mesmo tenha ocorrido em consequiência da liberação de parte da variabilidade genética potencial.

As estimativas da variância genética aditiva obtidas (Tabela 3) foram coerentes com as relatadas por Aguiar (1986) e Carvalho et al. (1994, 1995), com progênies de meios-irmãos do ciclo original, na média de três locais. Os valores das estimativas relatadas neste trabalho foram concordantes também com as estimativas obtidas em diversas populações de milho brasileiras (Ramalho, 1977), e ressaltam a grande variabilidade genética presente na população CMS-453.

Os valores dos coeficientes de herdabilidade, no sentido restrito para médias de progênies de meiosirmãos $\left(\mathrm{h}^{2} \mathrm{~m}\right)$ em todos os ciclos, foram mais elevados que os valores expressos para indivíduos $\left(\mathrm{h}^{2}\right)(\mathrm{Ta}-$ bela 3), o que evidencia que a seleção entre progêni-

TABELA 3. Estimativas obtidas referentes à variância genética entre progênies $\left(\sigma_{p}^{2}\right)$, variância genética aditiva $\left(\sigma_{\mathrm{A}}^{2}\right)$, variância da interação progênies $\mathrm{x}$ locais $\left(\sigma_{\mathrm{pxl}}^{2}\right)$, coeficientes de herdabilidade no sentido restrito de médias de progênies $\left(h^{2}\right)$ e quanto à seleção massal $\left(h^{2}\right)$, coeficientes de variação genética (C.Vg.), índices de variação (b) e ganhos genéticos entre e dentro de progênies de meiosirmãos (Gs), considerando-se o caráter peso de espigas, para a população de milho CMS-453, em três ciclos de seleção. Região Nordeste do Brasil, 1995 a 1997.

\begin{tabular}{|c|c|c|c|c|c|c|c|c|c|c|c|}
\hline \multirow[t]{2}{*}{ Ciclo $^{1}$} & \multirow[t]{2}{*}{$\hat{\sigma}_{p}^{2}$} & \multirow[t]{2}{*}{$\hat{\sigma}^{2}{ }_{A}$} & \multirow[t]{2}{*}{$\hat{\sigma}_{\mathrm{pxl}}^{2}$} & \multirow[t]{2}{*}{$\hat{\mathrm{h}}_{\mathrm{m}}^{2}$} & \multirow[t]{2}{*}{$\hat{\mathrm{h}}^{2}$} & \multirow{2}{*}{$\hat{\mathrm{C}} \mathrm{Vg}$. } & \multirow[t]{2}{*}{$\mathrm{b}$} & \multicolumn{2}{|c|}{$\hat{\text { Gs entre }}{ }^{2}$} & \multicolumn{2}{|c|}{$\hat{G}_{s}$ dentro ${ }^{2}$} \\
\hline & & & & & & & & (g/planta) & $(\%)$ & (g/planta) & $(\%)$ \\
\hline Original & $99,50 \pm 20,30$ & $398,16 \pm 81,20$ & 202,15 & 52,16 & 27,76 & 9,70 & 0,80 & 7,15 & 6,98 & 7,58 & 7,41 \\
\hline I & $25,84 \pm 7,48$ & $103,38 \pm 29,92$ & 46,35 & 38,00 & 7,86 & 3,76 & 0,40 & 6,75 & 5,06 & 1,88 & 1,41 \\
\hline II & $37,30 \pm 8,60$ & $149,20 \pm 34,40$ & 21,18 & 48,69 & 16,14 & 6,67 & 0,60 & 10,82 & 11,86 & 3,25 & 3,56 \\
\hline
\end{tabular}

1 Ciclo original: Neópolis, Lagarto e Cruz das Almas, 1995; ciclo I: Neópolis, Cruz das Almas e Nossa Senhora das Dores, 1996; ciclo II: Umbaúba e Nossa Senhora das Dores, 1997.

2 Para cálculo do ganho genético entre e dentro de progênies considerou-se a relação $\sigma_{\mathrm{d}}^{2}=10 \sigma_{\mathrm{e}}^{2}$, conforme Gardner (1961). 
es de meios-irmãos deve ser mais eficiente que a seleção individual para o presente caso, corroborando os resultados relatados por Santos \& Naspolini Filho (1986), Pacheco (1987), Carvalho et al. (1994, 1995, 1998b).

As estimativas obtidas dos coeficientes de variação genética e dos índices de variação b (Tabela 3) mostraram as mudanças ocorridas na variabilidade genética da população nos três ciclos de seleção. Os valores dos coeficientes de variação genética refletem uma maior variação entre as progênies nos ciclos original e II, do que entre as progênies no ciclo I. Os índices b mostraram as mesmas tendências registradas com relação aos coeficientes de variação genética, e suas magnitudes expressaram também a variabilidade apresentada pela população, cujos valores são semelhantes aos relatados por Carvalho et al. (1994, 1998b), em avaliação realizadas em dois e três locais. Para Vencovsky \& Barriga (1992), quando o coeficiente $b$ atinge o valor $1,0 \mathrm{ou}$ mais, na experimentação com progênies de meiosirmãos, indica uma situação muito favorável para a seleção. Contudo, deve-se salientar que estimativas obtidas pela seleção realizada em mais de um local, estando, assim, pouco inflacionadas pela interação progênies x locais, atingem valores inferiores a 1,0, conforme tem sido detectado por Aguiar (1986), Pacheco (1987), Carvalho et al. (1994, 1995, 1998a, 1998b).

Ressalta-se, também, que, na literatura, resultados de diversos trabalhos demonstraram a presença de variabilidade em várias populações, capaz de conseguir progressos com a seleção. As estimativas obtidas em relação aos coeficientes de variação genética e dos índices $b$ nesses trabalhos oscilaram de $2,10 \%$ a $15,31 \%$ e $0,10 \%$ a $0,88 \%$, respectivamente (Cunha, 1976; Ramalho, 1977; Santos, 1985; Aguiar, 1986; Pacheco, 1987; Carvalho et al., 1994). Os autores mencionados consideraram as populações como potencialmente promissoras, tendo em vista a quantidade de variabilidade genética que foi exigida.

Os ganhos estimados com a seleção entre e dentro de progênies foram $6,98 \%$ e $7,41 \%$, totalizando $14,39 \%$ no ciclo original; $5,06 \%$ e $1,41 \%$, totalizando $6,47 \%$ no ciclo I; $11,86 \%$ e $3,56 \%$, totalizando $15,42 \%$, no ciclo II. Na média dos três ciclos, obteve-se um ganho estimado de $11,62 \%$, sendo da mesma magni- tude daquele registrado por Paterniani (1967), com a população Dente Paulista, e superior quando comparados aos relatados por Webel \& Lonquist (1967) e Carvalho et al. (1995), obtidas também na média de três ciclos de seleção. Tais estimativas evidenciam, mais uma vez, o potencial genético desta população em responder à seleção. Vários trabalhos na literatura têm relatado progressos genéticos esperados com a seleção entre e dentro de progênies de meios-irmãos e uso de sementes remanescentes, sendo, porém, um ciclo completado em dois anos (Webel \& Lonquist, 1967; Paterniani, 1968; Compton \& Bahadur, 1977). Os resultados obtidos neste trabalho foram relativamente concordantes com os detectados pelos autores supracitados, devendo-se, no entanto, chamar a atenção para a sua superioridade quando são feitas comparações de um ano para dois anos.

Considerando que as diferenças entre as médias da testemunha BR 106 refletiram as diferenças ambientais e interações de um ciclo para outro, podese ajustar as médias dos ciclos das progênies avaliadas, para torná-las compatíveis. Assim, o ganho acumulado obtido no segundo ciclo de seleção foi de $350 \mathrm{~kg} / \mathrm{ha}$, correspondendo a $6 \%$, o que fornece um ganho obtido de $3,0 \%$ por ciclo/ano. Na maioria dos casos, segundo Sawazaki (1979) pode existir concordância entre os valores dos ganhos obtido e esperado, a exemplo de Segovia (1976), que registrou um ganho esperado de $3,25 \%$, e um observado de $3,30 \%$, discordando dos resultados do presente trabalho, em que o ganho médio esperado por ciclo/ano foi de $11,62 \%$, e o obtido foi de $3 \%$. Valores mais discordantes foram detectados por Mirando Filho $(1977 ; 1979)$, que registrou valores de $8,8 \%$ para o ganho esperado e 1,8\% para o obtido, e atribuiu tais resultados como causas das discrepâncias do uso da constante $\mathrm{K}$ (diferencial de seleção estandardizado), principalmente quando se trata de seleção não truncada, e a baixa eficiência da seleção massal entre progênies. Santos \& Naspolini Filho (1986) também obtiveram valores do progresso esperado $(10,34 \%)$, superestimados quando comparados ao progresso médio observado $(2,70 \%)$, em relação à média das testemunhas.

Tratando-se de uma população de alta qualidade protéica, na recombinação foram utilizadas as progê- 
nies que associaram boas produtividades médias de espigas, na média dos locais, a altos teores de triptofano e lisina. Observaram-se, também, outros caracteres agronômicos desejáveis, tais como altura da planta e da espiga, acamamento, quebramento do colmo e empalhamento. Os teores de triptofano e lisina na proteína, na média dos três ciclos de seleção, foram de $0,88 \%$ e $3,91 \%$, respectivamente, sendo ligeiramente superiores aos detectados na variedade BR 451, de alta qualidade protéica, os quais foram de $0,8 \%$ de triptofano/proteína e 3,6\% de lisina/proteína, respectivamente, o que evidencia a alta qualidade protéica da população CMS-453. Associando-se, então, o bom potencial produtivo das progênies da população CMS-453 às magnitudes das estimativas dos parâmetros genéticos obtidos e à alta qualidade protéica, percebe-se que há grandes possibilidades de obter respostas à seleção para aumento da produtividade e adaptação, mantendose em níveis bastante satisfatórios os teores de triptofano e lisina, com a continuidade do programa de melhoramento.

\section{CONCLUSÕES}

1. A alta capacidade produtiva da população CMS-453 e as magnitudes das estimativas dos parâmetros genéticos evidenciam a resposta do material à seleção para aumento da produtividade.

2. Os ganhos médios esperado e obtido com a seleção entre e dentro das progênies de meios-irmãos são de $11,62 \%$ e $3,00 \%$, respectivamente, na média dos ciclos de seleção.

3. Após a realização do ciclo II de seleção, a população CMS-453 ainda possui variabilidade genética suficiente para continuar em um programa de melhoramento.

\section{REFERÊNCIAS}

AGUIAR, P.A. Avaliação de progênies de meios-irmãos de milho CMS-39 em diferentes condições de ambientes. Lavras : ESAL, 1986. 68p. Dissertação de Mestrado.

CARDOSO, M.J.; CARVALHO, H.W.L. de; PACHECO, C.A.A.P.; SANTOS, M.X. dos; LEAL, M. de L. da S. Adaptabilidade e estabilidade de cultivares de mi- lho no Estado do Piauí no biênio 1993/94. Revista Científica Rural, Bagé, v.2, n.1, p.35-44, 1997.

CARVALHO, H.W.L. de; MAGNAVACA, R.; LEAL, M. de L. da S. Estabilidade da produção de cultivares de milho no Estado de Sergipe. Pesquisa Agropecuária Brasileira, Brasília, v.27, n.7, p.1073-1082, jul. 1992.

CARVALHO, H.W.L. de; PACHECO, C.A.A.P.; SANTOS, M.X. dos; GAMA, E.E.G. e; MAGNAVACA, R. Potencial genético da população de milho (Zea mays L.) CMS 53 para fins de melhoramento no Nordeste brasileiro. Ciência e Prática, Lavras, v.19, n.1, p.37-42, 1995.

CARVALHO, H.W.L. de; PACHECO, C.A.A.P.; SANTOS, M.X. dos; GAMA, E.E.G. e; MAGNAVACA, $\mathrm{R}$. Três ciclos de seleção entre e dentro de famílias de meios-irmãos na população de milho BR 5011 no Nordeste brasileiro. Pesquisa Agropecuária Brasileira, Brasília, v.33, n.5, p.713-720, maio 1998a.

CARVALHO, H.W.L. de; PACHECO, C.A.A.P.; SANTOS, M.X. dos; GAMA, E.E.G. e; MAGNAVACA, R. Três ciclos de seleção entre e dentro de progênies de meios-irmãos na população de milho BR 5028-São Francisco, no Nordeste brasileiro. Pesquisa Agropecuária Brasileira, Brasília, v.29, n.11, p.1727-1733, nov. 1994

CARVALHO, H.W.L. de; SANTOS, M.X. dos; LEAL, M. de L. da S.; PACHECO, C.A.A.P. Melhoramento genético na variedade de milho BR 5028-São Francisco no Nordeste brasileiro. Pesquisa Agropecuária Brasileira, Brasília, v.33, n.4, p.441-448, abr. 1998 b.

COMPTON, W.A.; BAHADUR, K. Ten cycles of progress from modified ear-to-row selection in corn. Crop Science, Madison, v.17, p.378-380, 1977.

CUNHA, M.A.P. Seleção entre e dentro de famílias de meios-irmãos de milho (Zea mays L.) ESALQ HV-1. Piracicaba: ESALQ, 1976. 84p. Tese de Doutorado.

GARDNER, C.O. An evolution of effects of mass selection and seed irradiation with thermal neutrons on yield of corn. Crop Science, Madison, v.1, p.241-245, 1961.

HALLAUER, A.R.; MIRANDA FILHO, J.B. Quantitative genetics in maize breeding. 2.ed. Ames : Iowa State University Press, 1988. 468p.

LORDELLO, J.A.C. Parâmetros genéticos das populações de milho Piranão VD-2 e Piranão VF-1.

Pesq. agropec. bras., Brasília, v.35, n.8, p.1577-1584, ago. 2000 
Piracicaba : ESALQ, 1982. 62p. Dissertação de Mestrado.

MAGNAVACA, R.; PAIVA, E.; WINKLER, E.I.; CARVALHO, H.W.L.de; SILVA FILHO, M. de C.; PEIXOTO, M.I.V.V.D. Avaliação de populações de milho de alta qualidade protéica. Pesquisa Agropecuária Brasileira, Brasília, v.23, n.11, p.1263-1268, nov. 1988.

MIRANDA FILHO, J.B. Avaliação de famílias de meios-irmãos na população de milho ESALQ PB-1. Piracicaba: ESALQ, 1977. p.80-94. (Relatório Técnico-Científico, 11).

MIRANDA FILHO, J.B. Avaliação de famílias de meios-irmãos na população de milho ESALQ PB-1 de milho. Piracicaba : ESALQ, 1979. p.149-158. (Relatório Técnico-Científico, 13).

PACHECO, C.A.A.P. Avaliação de progênies de meios-irmãos na população de milho CMS-39 em diferentes condições de ambientes: $2^{\circ}$ ciclo de seleção. Lavras : ESAL, 1987. 100p. Dissertação de Mestrado.

PACHECO, C.A.A.P.; GUIMARÃES, P.E. de O.; PARENTONI, S.N.; LOPES, M.A.; SANTOS, M.X. dos; GAMA, E.E.G. e; VASCONCELOS, M.J.V.; CORREIA, L.A.; MEIRELLES, W.F. O desenvolvimento de milho de alta qualidade nutricional no Brasil. In: REUNIÓN LATINOAMERICANA DEL MAÍZ, 28., 1999, Sete Lagoas. Memórias. Sete Lagoas : EmbrapaCNPMS/CIMMYT, 1999. p.13-25.

PATERNIANI, E. Avaliação de métodos de seleção entre e dentro de famílias de meios-irmãos no melhoramento de milho (Zea mays L.). Piracicaba : ESALQ, 1968. 92p. Dissertação de Mestrado.

PATERNIANI, E. Selection among and within half-sib families in a Brazilian population of maize (Zea mays L.). Crop Science, Madison, v.7, n.3, p.212216, 1967.

RAMALHO, M.A.P. Eficiência relativa de alguns processos de seleção intrapopulacional no milho baseados em famílias não endógamas. Piracicaba : ESALQ, 1977. 122p. Dissertação de Mestrado.

SANTOS, M.X. dos. Estudo do potencial de duas raças brasileiras de milho (Zea mays L.) para fins de melhoramento. Piracicaba : ESALQ, 1985. 186p. Tese de Doutorado.

SANTOS, M.X. dos; NASPOLINI FILHO, W. Estimativas de parâmetros genéticos em três ciclos de seleção entre e dentro de famílias de meios-irmãos no milho (Zea mays L.) Dentado Composto Nordeste. Revista Brasileira de Genética, Ribeirão Preto, v.9, n.2, p.307-319, 1986.

SAWAZAKI, E. Treze ciclos de seleção entre e dentro de famílias de meios-irmãos para a produção de grãos no milho IAC-Maia. Piracicaba : ESALQ, 1979. 99p. Dissertação de Mestrado.

SCAPIM, C.A.; CARVALHO, C.G.P. de; CRUZ, C.D. Uma proposta de classificação dos coeficientes de variação para a cultura do milho. Pesquisa Agropecuária Brasileira, Brasília, v.30, n.5, p.683686, maio 1995.

SEGOVIA, R.T. Seis ciclos de seleção entre e dentro de famílias de meios-irmãos no milho (Zea mays L.) Centralmex. Piracicaba : ESALQ, 1976. 98p. Tese de Doutorado.

VENCOVSKY, R. Herança quantitativa. In: PATERNIANI, E. (Ed.). Melhoramento e produção do milho no Brasil. Piracicaba : ESALQ, 1978. p.122-201.

VENCOVSKY, R.; BARRIGA, P. Genética biométrica no fitomelhoramento. Ribeirão Preto : Sociedade Brasileira de Genética, 1992. 496p.

VIANNA, R.T.; SILVA, J.C. Comparação de três métodos de análise de variância em experimentos em "látice" em milho (Zea mays L.). Experientiae, Viçosa, v.24, p.21-41, 1978.

WEBEL, O.D.; LONQUIST, J.H. An evaluation of modified ear-to-row selection in a population of corn (Zea mays L.). Crop Science, Madison, v.7, p.651-655, 1967. 